\title{
Three Dimensional Space Vector Modulation Theory: Practices without Proofs
}

\author{
Bhaskar Bhattacharya, Ajoy Kumar Chakraborty \\ Department of Electrical Engineering, National Institute of Technology, Agartala, Tripura, India
}

\begin{abstract}
Article Info
Article history:

Received Apr 30, 2015

Revised Sep 4, 2015

Accepted Oct 2, 2015

\section{Keyword:}

$\alpha-\beta-\gamma$ frame

Space Vector

Switching state vector

ABSTRACT

In three dimensional (3D) space vector modulation (SVM) theory with $\alpha-\beta-\gamma$ frame there are some issues which are well known and are widely practiced being quite obvious but without any proof so far. In this paper necessary scientific foundations to those issues have been provided. The foremost of these issues has been with the frame of reference to be considered in 3D SVM applications for unbalanced three phase systems. Although for balanced three phase systems there has been no controversy with $\alpha-\beta$ frame as the frame of reference but in $3 \mathrm{D}$ it has not yet been established which one, $\alpha-\beta-\gamma$ frame or the $a-b-c$ frame, is mathematically correct. Another significant issue addressed in this work has been to ascertain the exact reason when a three phase system has to be represented in 2D or 3D space to apply SVM. It has been presented for the first time in this work that the key factor that determines whether $3 \mathrm{D}$ or $2 \mathrm{D}$ SVM has to be applied depends on the presence of time independent symmetrical components in a three phase ac system. Also it has been proved that the third axis, the $\gamma$-axis, represents the time independent quantity and that it must be directed perpendicular to the $\alpha$ $\beta$ plane passing through the origin.
\end{abstract}

Copyright (C) 2016 Institute of Advanced Engineering and Science. All rights reserved.

\section{Corresponding Author:}

Bhaskar Bhattacharya,

Department of Electrical Engineering,

National Institute of Technology Agartala,

Barjala, Jirania, Agartala, Tripura, India-799046.

Email: bhaskarohmm@gmail.com

\section{INTRODUCTION}

Space Vector theory is based upon the d-q-0 and $\alpha-\beta-\gamma$ transformation theories presented by Park (1929) [1] \& Clarke et al. (1951) [2] respectively. Originally, it was developed for studies of electrical machines [3]. Since then there have been many applications of Space Vector Modulation (SVM) in power converters and ac drives [3]-[7]. Electrical machines being balanced three phase loads without zero sequence components such studies have remained confined to $\alpha-\beta$ transformation only and the SVM applied was 2D SVM. The ability of representing a three phase balanced system by a single vector applying $\alpha-\beta$ transformation and the successful applications of 2D SVM in different areas of power converter applications e.g. dc drives, ac drives, inverters, rectifiers, and different flexible AC transmission system (FACTS) devices for power quality applications [3]-[15] led researchers to apply SVM for three phase unbalanced systems.

In an unbalanced system the $\gamma$-component is not zero so the number of dimensions of the active space increases from 2 to 3, making the 3D SVM as the applicable SVM. The first 3D SVM was reported by Zhang et al. [16] in 1997. In [16], $\alpha-\beta-\gamma$ frame has been used with the axis for $\gamma$-component shown as a perpendicular to the $\alpha-\beta$ plane and passing through the origin. It has been stated therein, "With the additional neutral leg, the space vector modulation control is much more complex and there is no precedent literature addressing this issue". Using 3D SVM in $\alpha-\beta-\gamma$ frame has remained an area comparatively less worked and less reported [17]-[21]. To overcome the complexities and difficulties of 3D SVM in $\alpha-\beta-\gamma$ frame, Perales et 
al. [22] proposed to use a-b-c coordinates for 3D SVM. Since then a number of works using a-b-c frame have been reported [23]-[26]. But none of these papers have justified a-b-c frame as a valid frame to mathematically represent a 3D space or any vector in a 3D space. A comparison of shunt active power filter with load current detection and with source current detection but without reference to space vector theory has been presented in [27].

The paper has been organized in different sections. In Section-2 the mathematically appropriate frame of reference for 3D SVM analysis has been established. In Section-3, the necessary and essential condition for a three phase system to be represented as a $2 \mathrm{D}$ vector in accordance to space vector theory has been presented and in Section-4 the logic for mapping the one-dimensional vector representing zero sequence component of symmetrical components of a three phase system along the $\gamma$-axis has been presented. Conclusion has been presented in Section-5.

\section{THE CORRECT MATHEMATICAL FRAME FOR 3D ANALYSIS: $\alpha-\beta-\gamma$ OR A-B-C?}

Space vector theory is an effective analytical tool to analyze three phase systems. In this method any time-varying three phase system is converted from time domain to a set of two vectors in space domain. If $\mathrm{v}_{\mathrm{a}}(\mathrm{t}), \mathrm{v}_{\mathrm{b}}(\mathrm{t})$, and $\mathrm{v}_{\mathrm{c}}(\mathrm{t})$ be three phase quantities in a-b-c plane then the system can be represented by a space vector $\bar{V}$ which is the resultant of two vector quantities $\bar{V}_{S}$ and $\bar{V}_{Z}$ as:

$$
\overline{\mathrm{V}}=\overline{\mathrm{V}}_{\mathrm{S}}+\overline{\mathrm{V}}_{\mathrm{Z}}
$$

where, $\quad \vec{V}_{S}=\left(V_{\alpha}+j V_{\beta}\right)$, a 2D space vector in the $\alpha-\beta$ complex plane, shown in Figure 1, with real axis unit vector $v_{\alpha}$ directed along phase quantity $v_{a}(t)$ in the a-b-c plane and $j=\sqrt{-1}$

$=\frac{2}{3}\left(\vec{a}^{0} v_{a}(t)+\vec{a}^{1} v_{b}(t)+\vec{a}^{2} v_{c}(t)\right)$, where: $a=e^{j 2 \pi / 3}=\left(-\frac{1}{2}-j \frac{\sqrt{3}}{2}\right)$

and, $\quad \overrightarrow{\mathrm{V}}_{\mathrm{Z}}=\frac{1}{3}\left(\mathrm{v}_{\mathrm{a}}(\mathrm{t})+\mathrm{v}_{\mathrm{b}}(\mathrm{t})+\mathrm{v}_{\mathrm{c}}(\mathrm{t})\right)$
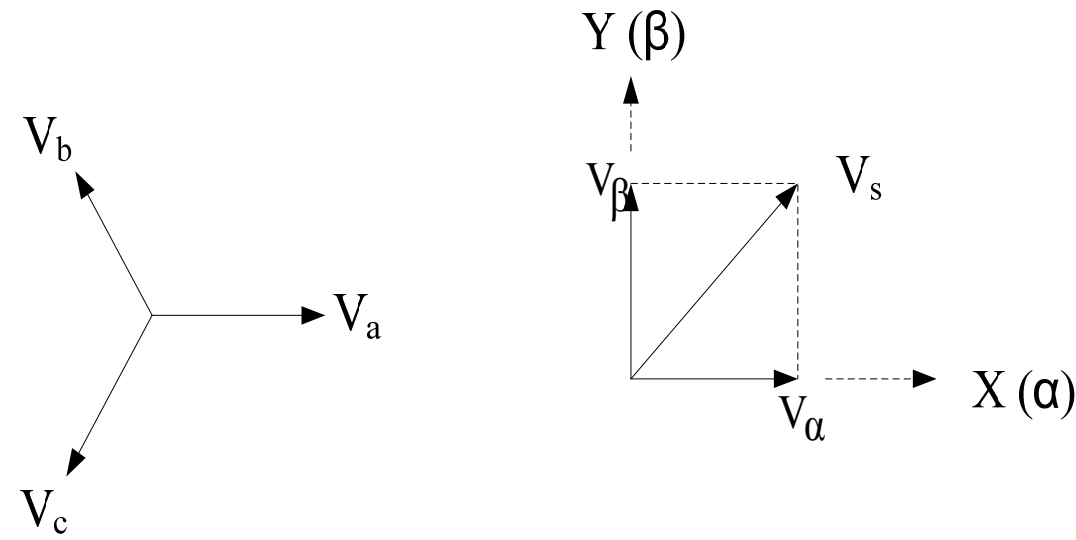

Figure 1. Transformation from a-b-c to $\alpha-\beta$

If the sum of three phase quantities be zero then $\vec{V}_{Z}$ is zero and (1) becomes:

$\overline{\mathrm{V}}=\overline{\mathrm{V}}_{\mathrm{S}}$

Application of Clarke transformation converts the same three phase system of $v_{a}(t), v_{b}(t)$ and $v_{c}(t)$ from a-b-c to $\alpha-\beta-\gamma$ frame. The transformation, when $v_{a}(t)+v_{b}(t)+v_{c}(t) \neq 0$, is as follows: 


$$
\left[\begin{array}{c}
\mathrm{v}_{\alpha} \\
\mathrm{v}_{\beta} \\
\mathrm{v}_{\gamma}
\end{array}\right]=\frac{2}{3}\left[\begin{array}{ccc}
1 & -1 / 2 & -1 / 2 \\
0 & \sqrt{3} / 2 & -\sqrt{3} / 2 \\
1 / 2 & 1 / 2 & 1 / 2
\end{array}\right]\left[\begin{array}{c}
\mathrm{v}_{\mathrm{a}} \\
\mathrm{vb}_{\mathrm{b}} \\
\mathrm{v}_{\mathrm{c}}
\end{array}\right]
$$

But for the system where $\mathrm{v}_{\mathrm{a}}(\mathrm{t})+\mathrm{v}_{\mathrm{b}}(\mathrm{t})+\mathrm{v}_{\mathrm{c}}(\mathrm{t})=0$, the Clarke transformation is given in $(6)$.

$$
\left[\begin{array}{l}
\mathrm{v}_{\alpha} \\
\mathrm{v}_{\beta}
\end{array}\right]=\frac{2}{3}\left[\begin{array}{ccc}
1 & -1 / 2 & -1 / 2 \\
0 & \sqrt{3} / 2 & -\sqrt{3} / 2
\end{array}\right]\left[\begin{array}{c}
\mathrm{v}_{\mathrm{a}} \\
\mathrm{v}_{\mathrm{b}} \\
\mathrm{v}_{\mathrm{c}}
\end{array}\right]
$$

Clarke transformation equations (5) and (6) have been developed with phase-a vector $\overrightarrow{v_{a}}$ aligned along $\alpha$-axis and the $\beta$-axis located at right angles to the $\alpha$-axis. All the vectors $\vec{v}_{\mathrm{a}}, \vec{v}_{\mathrm{b}}, \overrightarrow{\mathrm{v}}_{\mathrm{c}}, \overrightarrow{\mathrm{v}}_{\alpha} \& \overrightarrow{\mathrm{v}}_{\beta}$ are on the same plane, a 2D space as shown in Figure 1. This 2D space is the $\alpha-\beta$ plane as well as the a-b-c plane with origins of both frames located at the same point. Hence $a-b-c$ frame has its all three axes on the same plane but for a frame to represent a 3D space all its axes cannot lie on one plane as per mathematics. So a-b-c frame is not the correct frame for analyzing any $3 \mathrm{D}$ space vector. It can be seen from (2) that a $2 \mathrm{D}$ vector $\overline{\mathrm{V}}_{S}$ lies on the a-b-c plane i.e. the $\alpha-\beta$ plane. To mathematically represent a $3 \mathrm{D}$ vector $\overrightarrow{\mathrm{V}}$ as in (1), another 1D vector $\bar{V}_{Z}$ has to be outside the $\alpha-\beta$ plane where the $2 D$ vector $\bar{V}_{S}$ lies. In $\alpha-\beta-\gamma$ frame $\bar{V}_{Z}$ is mapped along a third direction called $\gamma$-axis and hence it is the correct mathematical frame for 3D space vector analysis.

\section{CONDITION FOR REPRESENTING A THREE PHASE SYSTEM WITH A 2D VECTOR}

As per symmetrical component theory [28], any single phase quantity of a three phase system can be expressed as a function of three vectors representing corresponding phase of three different balanced systems: positive sequence, negative sequence and zero sequence. While positive and negative sequence components are functions of time the zero sequence component is time independent. Equations (2) and (6) reveal that the zero sequence components only have been left out of the $\alpha-\beta$ complex plane. Expression of $\overline{\mathrm{V}}_{\gamma}$ computed from (5) and the right hand side (r.h.s) of (3) are equal i.e.

$$
\overline{\mathrm{V}}_{\mathrm{Z}}=\overline{\mathrm{V}}_{\gamma}
$$

Hence the time independent zero sequence component $\bar{V}_{\gamma}$ does not lie on the $\alpha-\beta$ plane. This fact leads to the conclusion that the condition for representing a three phase system with a $2 D$ vector is that the system will not have any time-invariant symmetrical component. It does not exclude the negative sequence symmetrical components i.e. a three phase system having negative sequence components but without any zero sequence component can be represented by a $2 \mathrm{D}$ vector on $\alpha-\beta$ plane. This is different from the prevailing concept of space vector in $2 \mathrm{D}$ or in $3 \mathrm{D}$ based upon the balanced or unbalanced state of the three phase system under conversion.

\section{MAPPING ZERO SEQUENCE SYMMETRICAL COMPONENT ALONG $\gamma$-AXIS IN $\alpha-\beta-\gamma$ FRAME}

That $\alpha$ and $\beta$ axes of $\alpha-\beta$ plane with mutually perpendicular directions have been clearly defined in Clarke transformation but the direction of $\gamma$-axis of $\alpha-\beta-\gamma$ frame has not been so defined. In the literature so far the $\gamma$-axis of the $\alpha-\beta-\gamma$ frame has been shown to be directed in a direction mutually perpendicular to both $\alpha$ and $\beta$ axes but why it shall be so directed has not been found in literature.

It has been noted that the space vector representation of a three phase system having zero sequence components is a three dimensional vector. Combining equations (1) and (7) the general form of the 3D space vector for such a three phase system is, $\bar{V}=\bar{V}_{S}+\bar{V}_{\gamma}$ i.e. the resultant of a $2 \mathrm{D}$ vector $\overline{\mathrm{V}}_{\mathrm{S}}$ on $\alpha-\beta$ plane and a 1D vector $\bar{V}_{\gamma}$ along an axis $-\gamma$ which is not on the $\alpha-\beta$ plane. The direction of $\gamma$-axis of $\alpha-\beta-\gamma$ frame has not been clearly defined as $\alpha$ and $\beta$ axes have been. To satisfy the demand of symmetrical component facts that each individual phase mapped on $\alpha-\beta$ plane must have equal share of zero sequence components implies that $\bar{V}_{\gamma}$

Three Dimensional Space Vector Modulation Theory: Practices without Proofs (Bhaskar Bhattacharya) 
has to be so located and directed that it remains common to each individual phase in identical manner. Hence the only logical direction for $\gamma$-axis is along the line perpendicular to $\alpha$ and $\beta$ axes and passing through their point of intersection. This makes $\alpha-\beta-\gamma$ frame exactly analogous to Cartesian frame. Access to Cartesian frame opens up possibility of applying mathematical tools in space vector theory applications.

\section{CONCLUSION}

This work has provided the much needed scientific proofs for some hypotheses of 3D SVM theory. These hypotheses have been taken for granted without any proof on the ground that they are obvious and well known. It has been shown that between $\alpha-\beta-\gamma$ and a-b-c frames, the $\alpha-\beta-\gamma$ frame is the correct frame that fits the mathematical conditions essential to represent $3 \mathrm{D}$ space vectors. This work has determined the criterion that is necessary for a three phase unbalanced system to determine whether that has to be represented in a 3D space or in a $2 \mathrm{D}$ space. It has been justified here why the $\gamma$-axis in $\alpha-\beta-\gamma$ frame must be perpendicular to the $\alpha-\beta$ plane and why it must pass through the point of intersection of $\alpha \& \beta$ axes. With these confirmations, coordinate geometry or vector analyses can now be applied for 3D SVM applications using $\alpha-\beta-\gamma$ frame as it exactly matches Cartesian frame. The present work has provided the mathematical and logical explanations which had been so far missing in the theory.

\section{REFERENCES}

[1] R.H. Park, “Two Reaction Theory of Synchronous Machines", AIEE Transactions, vol. 48, pp 716-730, 1929.

[2] W.C. Duesterhoeft, et al, "Determination of Instantaneous Currents and Voltages by Means of Alpha, Beta, and Zero Components", Transactions of the American Institute of Electrical Engineers, vol. 70, no. 2, pp 1248-1255, 1951.

[3] K.P. Kovacs, et al, "Transient regimes of a.c. machines", Springer Verlag, 1995. (the original edition in German, 1959).

[4] G. Pfaff, et al., "Design and experimental results of a brushless ac servo drive", IEEE Transactions on Industry Applications, vol. IA-20, no. 4, pp 814-21, July/August 1984.

[5] H. Akagi, et al, "Instantaneous reactive power compensator comprising switching devices without energy storage components", IEEE Trans. on Industrial App., vol. IA-20, no. 3, May/June 1984.

[6] P. Vas, "Electrical Machines and Drives: A Space-Vector theory Approach", Oxford University Press, Oxford, UK, 808, 1992.

[7] D.W. Novotny, et al, "Vector Control and Dynamics of ac Drives", Oxford University Press, Oxford, UK, 440 p, 1996.

[8] P. Jayprakash, et al, "DSP Based Implementation of a Three-Phase, Four-Wire DSTATCOM for Voltage Regulation Power Quality Improvement", Industrial Electronics Conference 2009. IECON '09. 35th Annual Conference of IEEE, pp.3660-65, Nov 2009.

[9] R. Karthikeyan, et al, "An efficient multilevel inverter system for reducing THD with Space Vector Modulation", International Journal of Computer Applications, vol.23, no.2, pp.0975 - 8887, June 2011.

[10] M. Ucar, et al, "Control of 3-phase 4-leg active power filter under non-ideal mains voltage condition", Electric Power System Research, vol. 78, pp. 58-73, 2008.

[11] Yashpal, et al, "A Comparison of Three Topologies of Three Phase Four Wire UPQC for Power Quality Improvement", 16th National Power Systems Conference, pp. 227-232, 15-17th Dec. 2010.

[12] B. Singh, et al, "Reduced Rating VSC with a Zig-Zag Transformer for Current Compensation in a Three-Phase Four-Wire Distribution System", IEEE Transactions on Power Delivery, vol. 24, No. 1, pp. 249-59, January 2009.

[13] B.R. Lin, et al, "An eight-switch three-phase VSI for power factor regulated shunt active filter", EPSR, vol. 68, pp.157-165, 2004.

[14] O. Vodyakho, et al, "Novel Direct Current-Space-Vector Control for Shunt Active Power Filters Based on the Three-Level Inverter”, IEEE Transactions On Power Electronics, vol. 23, no. 4, pp. 1668-78, July 2008.

[15] O. Vodyakho, et al, "Three-Level Inverter-Based Shunt Active Power Filter in Three-Phase Three-Wire and FourWire Systems", IEEE Transactions On Power Electronics, vol. 24, No. 5, pp 1350-63, May 2009.

[16] R. Zhang, et al, "A three-phase inverter with a neutral leg with space vector modulation", in Proc. IEEE-APEC'97 Conf., pp. $857-63,1997$.

[17] R. Zhang, et al, "Three-Dimensional Space Vector Modulation for Four-Leg Voltage-Source Converters", IEEE Transactions On Power Electronics, vol. 17, No. 3, pp. 314-326, May 2002.

[18] Z. Juan, et al, "Simulation Research on a SVPWM Control Algorithm for a Four-Leg Active Power Filter", Journal of China University of Mining \& Technology, vol. 17, No. 4, pp. 0590 - 94, Dec. 2007.

[19] A. Chaghi, et al, "Four-Legged Active Power Filter Compensation for a Utility Distribution System", Journal of Electrical Engineering, vol. 55, no. 1-2, pp. 31-35, 2004.

[20] A.K. Chakraborty, et al, "A new three-dimensional space-vector modulation algorithm for four-leg inverter", 9th IET International Conference on advances in power system control, operation and management (APSCOM), pp. 1$6,2012$. 
[21] W. Wang, et al, "Space vector pulse-width modulation algorithm and DC-side voltage control strategy of threephase four-switch active power filters," IET Power Electronics, vol. 6, no. 1, pp: 125-135, Jan 2013.

[22] M.A. Perales, et al, "Three dimensional space vector modulation in $a b c$ coordinates for four leg voltage source converters", IEEE Power Electron. lett., vol. 1, no. 4, pp. 104-09, Dec. 2003.

[23] L.G. Franquelo, et al,"Three-Dimensional Space-Vector Modulation Algorithm for Four-Leg Multilevel Inverters using abc Coordinates", IEEE Transactions on Industrial Electronics, vol. 53, No. 2, pp. 458 - 466, April 2006.

[24] M.M. Prats, et al, "A 3-D space vector modulation generalized algorithm for multilevel converters", IEEE Power Electron. Lett., vol. 1, no. 4, pp. 110-14, Dec. 2003.

[25] G.W. Chang, et al, "An efficient $a-b-c$ reference frame-based compensation strategy for three-phase active power filter control", Electric Power Systems Research, vol. 60, pp.161-166, 2002.

[26] A. Garcesa, et al, "A generalized compensation theory for active filters based on mathematical optimization in ABC frame", Electric Power Systems Research vol. 90, pp. 1- 10, 2012.

[27] Y.Kusuma Latha, et al, "Control Strategy for Three Phase Shunt Active Power Filter with Minimum Current Measurements", International Journal of Electrical and Computer Engineering (IJECE), vol. 1, no. 1, pp. 31- 42, September 2011.

[28] C.L. Fortescue, "Method of symmetrical co-ordinates applied to the solution of polyphase networks", AIEE Trnsactions, vol. 37, part-II, pp. 1027-40, 1918.

\section{BIOGRAPHIES OF AUTHORS}

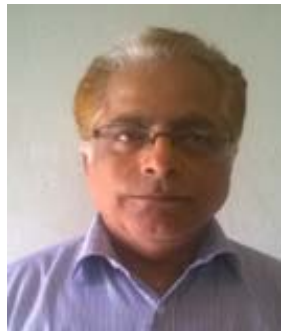

Bhaskar Bhattacharya graduated in Electrical Engineering from REC Durgapur, India in 1971 From 1972 to 1979 he worked as a Design Engineer in Development Consultants Pvt. Ltd., Kolkata, India. He worked as a self entrepreneur in electrical constructions from 1980 to 1986 and major works were construction of mini Hydel Power Station, 33KV Substation and 132KV Transmission Line Survey. From 1986 to 2008 he worked as Foreman Instructor at Tripura Institute of Technology, Tripura, India. He joined National Institute of Technology Agartala, Tripura, India in 2009 as a Teaching Assistant in Electrical Engineering Department and is a Research Fellow there. His current area of research is power quality issues.

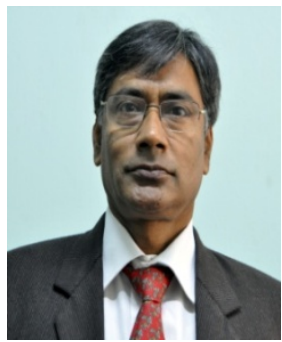

Ajoy Kumar Chakraborty obtained his L.E.E from state council of Engg. and technical education, West Bengal in 1979, B.E.E from Jadavpur University in 1987, M.Tech (Power System) from IIT, Kharagpur in 1990 and Ph.D (Engg) in 2007 from Jadavpur University respectively. He is currently working as an Associate Professor in the Department of Electrical Engineering, NIT Agartala, India. Before he joined the NIT Agartala in 2010, he was with college of Engineering \& Management, Kolaghat, India as a Professor. He has 16 years of teaching and 14 years of industrial experiences. His areas of interest include Application of soft computing techniques to different power system problems, Power Quality, FACTS \& HVDC and Deregulated Power System. He has published several papers in national and international conference and journals. He is a Fellow of Institution of Engineers (India) and Life member of ISTE. 